\title{
Association of traditional risk factors with coronary artery disease in nonagenarians: the primary role of hypertension
}

This article was published in the following Dove Press journal:

Clinical Interventions in Aging

20 November 2014

Number of times this article has been viewed

\section{Josef Yayan}

Department of Internal Medicine, Division of Pulmonary, Allergy and Sleep Medicine, Saarland University Medical Center, Homburg, Saarland, Germany
Correspondence: Josef Yayan Department of Internal Medicine, Division of Pulmonary, Allergy and Sleep Medicine, Saarland University Medical Center, Kirrberger Straße 100, 66424 Homburg, Saarland, Germany

$\mathrm{Tel}+496841 \quad 1621620$

Fax +49 684I I6 23602

Email josef.yayan@hotmail.com
Background: Previous studies have shown different relationships between traditional cardiovascular risk factors for coronary artery disease (CAD) in very elderly people. Although new associations with $\mathrm{CAD}$ have been reported, there is also evidence of the possibility of new therapeutic strategies for the treatment or prevention of CAD.

Design: This article retrospectively examines the possible association of traditional cardiovascular risk factors with CAD in very elderly people aged $>90$ years. This study represents the hypothesis that the elderly aged $>90$ years have a different cardiovascular profile with respect to CAD than patients $<90$ years old.

Methods: Data on all patients aged $>90$ years who received a cardiac catheterization were collected from hospital charts from the Department of Internal Medicine, Saarland University Medical Center, Germany, within the study period of 2004-2013. The cardiovascular risk profiles were compared in patients aged $>90$ years with and without CAD after cardiac catheterization.

Results: One hundred and six out of $67,976(0.2 \%$, mean age $91.6 \pm 1.8$ years, 40 female [37.7\%]; 95\% confidence interval [CI]: $0.1-0.2$ ), and out of a total of 114 of the very elderly patients, were found to have CAD. From the results of this study, the author could establish only a causal relationship between hypertension and CAD in very elderly people $(P=0.005)$. At best, this is just an association with a higher risk of CAD in this age group. Several studies with similar outcomes are needed to establish causality.

Conclusion: This study could find no link between CAD and traditional risk factors, except for hypertension.

Keywords: aging, hypertension, diabetes, hypercholesterolemia, hyperlipidemia, obesity

\section{Introduction}

Coronary artery disease (CAD) is defined in many studies and in the international and national clinical practice guidelines as the manifestation of atherosclerosis in the coronary arteries. ${ }^{1-9}$ The concept of CAD is not uniformly defined in the literature by all authors. There is also a somewhat broader definition. CAD is caused by a coronary insufficiency that, in addition to atherosclerosis, has numerous other underlying causes, such as inflammation. ${ }^{10-13}$ Fat, blood clots, connective tissue, and calcium deposits on the blood vessel walls, with an increasing reduction of the vessel cross-section, ultimately results in complete blockage. ${ }^{14-16}$ This causes impairment of the blood circulation and thus a decreased oxygen supply to the heart muscle. The result is a mismatch between oxygen demand and oxygen supply, which is referred to as ischemia or coronary insufficiency. ${ }^{17}$ 
Myocardial ischemia is manifested in various forms. Symptomatic CAD presents as chest pain caused by reversible myocardial ischemia; this is called angina pectoris. ${ }^{18}$ The likelihood of symptoms increases with the progression of the disease; these include cardiac arrhythmias, heart failure, and acute life-threatening complications such as heart attack and sudden cardiac death. ${ }^{19-23} \mathrm{CAD}$ is manifested clinically as acute coronary syndrome (ACS). The term ACS summarizes the immediately life-threatening stages of coronary heart disease, unstable angina, non-ST-segment elevation myocardial infarction (NSTEMI), and ST-segment elevation myocardial infarction (STEMI). ${ }^{24}$

$\mathrm{CAD}$ is a chronic disease that progresses over a period of years to decades. ${ }^{25}$ There are well-known risk factors for CAD that the patient cannot influence, such as a genetic predisposition, as well as the age and sex of the patient. Conversely, the risk factors for CAD that the patient can influence are hypercholesterolemia in particular, as well as obesity, tobacco smoking, arterial hypertension, diabetes mellitus, a sedentary lifestyle, and psychosocial factors. ${ }^{26-28}$ The individual risk factors are perhaps not only additive, but together they disproportionately increase the risk for the occurrence of CAD. The major risk factors for CAD in terms of morbidity and mortality are hypercholesterolemia with tobacco smoking, arterial hypertension, and diabetes mellitus. ${ }^{29-33}$

Smokers have an increased risk of heart attack, depending on the number of cigarettes smoked daily and the number of years they have smoked. ${ }^{34}$ There is a linear relationship between blood pressure and the risk for developing CAD. Blood pressure values proportionally increase the risk of the occurrence of CAD with an increase in blood pressure. ${ }^{35}$ More than half of patients suffering from diabetes mellitus die from CAD; moreover, diabetics have an increased risk of developing $\mathrm{CAD}$ compared to nondiabetics. ${ }^{36} \mathrm{~A}$ cure - that is, the removal of the cause in the sense of removal of the deposits in the affected vessel walls - is currently not possible, but the increasing deterioration can be delayed or stopped. To accomplish this, there are a number of approaches, ranging from a change in diet to lifestyle change ${ }^{37}$ Furthermore, CAD can be treated with medication, therapeutic interventions using cardiac catheterization, and surgically. ${ }^{38}$

$\mathrm{CAD}$ in its acute forms of clinical presentation such as ACS is the most common cause of death in industrialized nations. ${ }^{39}$

There are reasons for the different risk profile for CAD in very elderly people. The assessment of cardiovascular risk factors for $\mathrm{CAD}$ in the elderly may not be as easy; thus, the identification and assessment of risk factors for CAD in the elderly presents something of a challenge. The traditional risk factors for CAD are independently associated with aging. ${ }^{40,41}$ Moreover, aging is itself a risk factor for CAD. ${ }^{42}$ The results of the risk profile for CAD in younger people should not be applied to the elderly. ${ }^{42}$ Elderly people have been historically underrepresented in epidemiological studies evaluating the cardiovascular risk factors for CAD. ${ }^{43}$

The author conducted the present investigation to better understand all the possible risk factors for CAD in very elderly people aged $>90$ years. Therefore, the author collected data on all patients of this age with $\mathrm{CAD}$ according to the International Classification of Diseases (ICD) from the hospital database at the Department of Internal Medicine, Saarland University Medical Center, Germany. The variety of tested risk factors for CAD in people over 90 years of age were arterial hypertension, diabetes mellitus, hypercholesterolemia, hyperlipidemia, obesity, tobacco smoking, and former smoking. CAD diagnosis was carried out after cardiac catheterization. The risk factors for CAD were compared in patients older than 90 years of age after the exclusion of CAD by performing cardiac catheterization. Only once we have identified the causes of CAD can we develop appropriately tailored therapies for all patients to take precautions against CAD.

\section{Materials and methods \\ Patients}

In this study, the traditional cardiovascular risk factors for CAD were retrospectively examined in patients aged $>90$ years using hospital chart data at the Department of Internal Medicine, Saarland University Medical Center, with a study period from 2004-2013.

The study population was composed of very elderly patients $>90$ years of age diagnosed with CAD, and the control group was composed of elderly patients $>90$ years of age without $\mathrm{CAD}$, as determined after cardiac catheterization. All patients $>90$ years who were treated at the internal medicine emergency room or in one of the internal departments were included in this study after receiving a cardiac catheterization. Individuals who received the cardiac catheterization of the predicating symptoms of CAD were categorized as having stable angina and ACS.

\section{Definition and diagnosis of CAD}

$\mathrm{CAD}$ has been defined as a chronic disease of the coronary arteries characterized by the manifestation of atherosclerosis with variable coronary artery stenosis, resulting in myocardial 
ischemia. CAD symptoms are classified as stable angina and ACS. ACS is a collective term for unstable angina, NSTEMI, and STEMI. The main symptom of coronary insufficiency is angina pectoris; angina pectoris involves localized retrosternal pain triggered by physical and mental stress. It usually subsides within 15 minutes or within 2 minutes after taking nitroglycerin spray. Such chest pain may spread to the neck, lower jaw, shoulder, back, left arm to the fingertips, or the upper abdomen. Unstable angina refers to angina pectoris occurring for the first time, as well as a worsening of symptoms in pain intensity and duration of episodes.

NSTEMI was described for unstable angina and myocardial infarction with an increase of cardiac enzymes such as high-sensitivity cardiac troponin $\mathrm{T}$ without ST-segment elevation on electrocardiogram. A 12-lead electrocardiogram was used at rest for the temporary recording of the sum of the electrical activity of the heart for diagnosis of STEMI or cardiac arrhythmias in all patients. Typical STsegmental change in the electrocardiogram for STEMI was considered ST-segment elevation $>0.1 \mathrm{mV}$ in at least one derivation. The diagnosis of CAD was made after cardiac catheterization.

The classification of CAD was performed in each case according to the latest edition of the ICD (I25.11-I25.13) from 2004-2013. CAD injuries were categorized as 1-, $2-$, or 3-vessel. Further, examiners visually estimated the degree of stenosis diameter as a percentage of the cardiac catheterization, as per the stenosis morphology classification recommendations of the American College of Cardiology/ American Heart Association. ${ }^{44}$

\section{Risk factors categorization}

The author compared the cardiovascular risk factors in accordance with the guidelines of the International Atherosclerosis Society, ${ }^{45}$ such as arterial hypertension, diabetes mellitus, hypercholesterolemia, hyperlipidemia, obesity, tobacco smoking, and former smoking in very elderly patients aged $>90$ years with and without CAD (ICD I25.0-I25.10) after completing cardiac catheterization. Arterial hypertension was described as a condition in which the blood pressure of the arterial vascular system is chronically elevated. According to the World Health Organization (WHO), ${ }^{46}$ hypertension can be diagnosed with a systolic blood pressure of at least $140 \mathrm{mmHg}$ or a diastolic blood pressure of at least $90 \mathrm{mmHg}$ (ICD I10.90). New guidelines have raised the target for treatment of high blood pressure from below 140/90 to below 150/90 for people aged 60 years and older, unless they have diabetes or chronic kidney disease. Manifestation of hypertension was described as a known history of hypertension where the patient has been treated with drugs. The methods of measurement of blood pressure were the indirect method following Riva-Rocci: 24-hour blood pressure measurement, and DINAMAP ${ }^{\circledR}$ blood pressure monitor (GE Healthcare Europe GmbH, Freiburg, Germany).

Diabetes mellitus (ICD E14.90) was diagnosed as a chronic metabolic disease based on an absolute or relative lack of insulin with elevated blood glucose levels when fasting values were $>126 \mathrm{mg} / \mathrm{dL}$ or occasionally when a measured value $>200 \mathrm{mg} / \mathrm{dL}$ was detected in the serum of the patients. Blood glucose was determined in the serum of all patients using serum Monovette ${ }^{\circledR} 4.7 \mathrm{~mL}$ (brown top; SARSTEDT, Nümbrecht, Germany) blood collection system with a multifly blood collection needle.

The determination of blood lipids was carried out after 12 hours of fasting in all patients after blood collection in lithium heparin SARSTEDT Monovette ${ }^{\circledR} 4.7 \mathrm{~mL}$ (orange top) with a multifly blood collection needle as an enzymatic colorimetric test using the cobas c 701 system (Hoffman-La Roche Ltd., Basel, Switzerland). As hypercholesterolemia (ICD E78.0) is considered a lipid metabolic disorder characterized by elevated blood cholesterol levels of $>200 \mathrm{mg} / \mathrm{dL}$, hyperlipidemia (ICD E78.2-E78.3) is mainly diagnosed through elevated triglycerides in the blood plasma of patients. The reference range for hypertriglyceridemia has been specified as $>200 \mathrm{mg} / \mathrm{dL}$ in blood plasma.

Obesity (ICD E66.99) was defined as excessive growth of adipose tissue in the body. The transition from overweight to obesity was achieved with a body mass index (BMI) of $30 \mathrm{~kg} / \mathrm{m}^{2}$ as an adipose tissue type by calculating the body weight in kilograms divided by height in meters squared. Nicotine abuse (ICD F17.1) was designated as the abusive consumption of products that contain nicotine, including cigarettes, cigars, and other tobacco products. The study population was categorized into smokers, former smokers, and nonsmokers. The quantification of tobacco smoking by measuring in terms of packs per year was not considered in this study because the harmful effect of nicotine was not the focus of the research.

\section{Comorbidities}

The author analyzed acute and chronic comorbidities as predisposing factors for the development of CAD in elderly people. Comorbidity was considered the presence of one or more additional disorders existing simultaneously with a primary disease. The additional disorder may also be a behavioral or mental disorder. The risk for acute disease after 
organ groups was compared in patients with and without CAD. All cancer-related diagnoses were included as a separate comorbidity. In addition, the lengths of hospital stays were compared between study and control groups.

\section{Ethics statement}

Due to the retrospective nature of the study protocol, the Medical Association of Saarland's Institutional Review Board waived the need for informed consent.

\section{Statistical analysis}

The data were expressed as proportion, mean, and standard deviation wherever appropriate. The author calculated 95\% confidence intervals (CIs) for the total number of patients with CAD. Odds ratios (OR) were calculated for cardiovascular risk factors for $\mathrm{CAD}$, sex, and acute and chronic comorbidities. A calculation of the chi-square test for four independent standard normal variables of two probabilities was used to compare the association between cardiovascular risk factors and stable angina, unstable angina, NSTEMI, or STEMI. Fisher's exact test for four variables of two probabilities was calculated for cardiovascular risk factors in different forms of CAD. The Mann-Whitney test was used to compare the duration of hospital stays between the two groups. The survival rates for the duration of hospital stays for both groups were calculated using the KaplanMeier method. All tests were expressed as two-tailed, and a $P$-value of $<0.05$ was considered to be statistically significant.

\section{Results}

In the hospital database, the author found 67,976 patients who underwent cardiac catheterization at the Department of Internal Medicine, University Hospital of Saarland, Germany, during the study period of 2004-2013. A total of 114 (45 female [39.4\%]) patients aged $>90$ years having had a cardiac catheterization met the inclusion criteria for this trial. A total of 106 of $67,976(0.2 \%, 95 \%$ CI: $0.1-0.2$, mean age $91.6 \pm 1.8$ years, 40 female [37.7\%]) patients aged $>90$ years had CAD (study group); in eight patients $(0.01 \%, 95 \%$ CI: $0-0.02$, mean age $90.9 \pm 1.1$ years, female $[62.5 \%])$, CAD was excluded by means of cardiac catheterization (control group). The author found a higher prevalence of CAD in males, but without increased risk (OR: 1.9, 95\% CI: 0.4-8.2, $P=0.409$ ).

Following the results of this study, the author identified an eight-fold higher cardiovascular risk of developing CAD in patients aged $>90$ years with arterial hypertension $(P=0.005$, Table 1$)$. There was a low number of patients with hypercholesterolemia. Statins were prescribed as standard of care for heart attack patients. Not all patients had primary hypertension; there were a few with secondary causes, such as kidney diseases, diabetic nephropathy, hyperthyroidism, benign prostate hyperplasia, etc (Table 2 ). Very elderly diabetics had three-fold and very elderly former smokers twofold increased risk for the development of CAD, but without a statistically significant difference (Table 1). Both groups were distinguished statistically according to the number of subjects of normal weight, although most of the patients in the study population were not overweight (Table 1).

The largest group in the study had 3-vessel CAD followed by those with 2-vessel CAD, and the smallest group had 1-vessel CAD (Table 3). A comparison of the traditional cardiovascular risk factors with the number of coronary arteries that were afflicted with CAD showed no statistical difference (Table 3).

The author found no statistical difference after a comparison of the traditionally tested cardiovascular risk factors with the clinical manifestation of CAD, such as stable angina or ACS (Table 4). From a total of 106 patients with CAD, 21 $(19.8 \%)$ patients had stable angina, $79(74.5 \%)$ patients had unstable angina, and six (5.7\%) patients had no stable angina or ACS. From a total of 79 patients with ACS, $36(45.6 \%)$ had NSTEMI, 27 (34.2\%) had STEMI, and 16 (20.3\%) had

Table I Cardiovascular risk factors in elderly people $>90$ years of age with and without CAD

\begin{tabular}{|c|c|c|c|c|c|}
\hline Risk factors & CAD $(n=106)(\%)$ & Without CAD (n=8) (\%) & Odds ratio & $95 \% \mathrm{Cl}$ & $P$-value \\
\hline Hypertension & $89(84)$ & $3(37.5)$ & 8.7 & $1.9-40$ & 0.005 \\
\hline Diabetes & $32(30.2)$ & I (I2.5) & 3.0 & $0.4-25.6$ & 0.310 \\
\hline Hypercholesterolemia & $2(1.9)$ & 0 & 0.4 & $0.02-9.2$ & 0.571 \\
\hline Hyperlipidemia & $26(24.5)$ & $2(25)$ & I & $0.2-5.1$ & 0.976 \\
\hline Obesity & $4(3.8)$ & $2(25)$ & 0.1 & $0.02-0.8$ & 0.026 \\
\hline Smoker & $4(3.8)$ & 0 & 0.7 & $0.04-15.1$ & 0.848 \\
\hline Former smoker & II (I0.4) & 0 & 2 & $0.1-37.8$ & 0.630 \\
\hline
\end{tabular}

Note: Significant $P$-values are shown in bold.

Abbreviations: $\mathrm{CAD}$, coronary artery disease; $\mathrm{Cl}$, confidence interval. 
Table 2 Comparison of chronic comorbidities in elderly people aged $>90$ years with and without CAD

\begin{tabular}{|c|c|c|c|c|c|}
\hline & CAD $(n=106)(\%)$ & Without CAD $(n=8)(\%)$ & Odds ratio & $95 \% \mathrm{Cl}$ & $P$-value \\
\hline Cardiovascular disease & $\mathrm{n}=92$ & $n=8$ & 1.2 & $0.5-3$ & 0.645 \\
\hline Aneurysm & $\mathrm{I}(0.9)$ & 0 & & & \\
\hline Cardiomyopathy & $3(2.8)$ & 0 & & & \\
\hline Carotid stenosis & $3(2.8)$ & I (I2.5) & & & \\
\hline Cor pulmonale & $6(5.7)$ & $2(25)$ & & & \\
\hline Hypertensive heart disease & $5(4.7)$ & $I(12.5)$ & & & \\
\hline Pacemaker & $12(11.3)$ & I (I2.5) & & & \\
\hline Peripheral arterial occlusive disease & $14(13.2)$ & 0 & & & \\
\hline State after syncope & $3(2.8)$ & 0 & & & \\
\hline Cardiac valvular defect & $50(47.2)$ & $3(37.5)$ & & & \\
\hline Pulmonary disease & $n=12$ & $\mathbf{n}=\mathbf{2}$ & 0.6 & $0.1-2.7$ & 0.489 \\
\hline Chronic obstructive pulmonary disease & $7(6.6)$ & $2(25)$ & & & \\
\hline Emphysema & $2(1.9)$ & 0 & & & \\
\hline Obstructive sleep apnea syndrome & $\mathrm{I}(0.9)$ & 0 & & & \\
\hline State after tuberculosis & $2(1.9)$ & 0 & & & \\
\hline Gastrointestinal diseases & $n=37$ & $n=I$ & 4.1 & $0.5-31.6$ & 0.170 \\
\hline Appendectomy & $\mathrm{I}(0.9)$ & 0 & & & \\
\hline Cholecystectomy & $14(13.2)$ & I (I2.5) & & & \\
\hline Colonic diverticula & $4(3.8)$ & 0 & & & \\
\hline Gallbladder disease & I (0.9) & 0 & & & \\
\hline Gastric carcinoma & $4(3.8)$ & 0 & & & \\
\hline Liver cysts & I (0.9) & 0 & & & \\
\hline Pancreatic disease & I (0.9) & 0 & & & \\
\hline Splenectomy & I (0.9) & 0 & & & \\
\hline State after bowel surgery & $3(2.8)$ & 0 & & & \\
\hline State after hepatitis & $3(2.8)$ & 0 & & & \\
\hline State after hernia operation & $4(3.8)$ & 0 & & & \\
\hline Kidney disease & $n=40$ & $n=3$ & 1.4 & $0.4-4.9$ & 0.606 \\
\hline Chronic renal failure & $25(23.6)$ & $3(37.5)$ & & & \\
\hline Contracted kidney & I $(0.9)$ & 0 & & & \\
\hline Diabetic nephropathy & $3(2.8)$ & 0 & & & \\
\hline Nephrectomy & $3(2.8)$ & 0 & & & \\
\hline Renal adenoma & $2(1.9)$ & 0 & & & \\
\hline Renal cysts & $5(5.7)$ & 0 & & & \\
\hline State after kidney stones & I (0.9) & 0 & & & \\
\hline Disease of the genitourinary system & $n=12$ & $\mathbf{n}=\mathbf{2}$ & 0.6 & $0.1-2.7$ & 0.489 \\
\hline Benign prostate hyperplasia & $3(2.8)$ & I (I2.5) & & & \\
\hline Hysterectomy & $\mathrm{I}(0.9)$ & 0 & & & \\
\hline Prostate cancer & $3(2.8)$ & I (I2.5) & & & \\
\hline Prostatectomy & $3(2.8)$ & 0 & & & \\
\hline State after bladder carcinoma & $2(1.9)$ & 0 & & & \\
\hline Thyroid disease & $n=4$ & $\mathbf{n}=\mathbf{I}$ & 0.4 & $0.04-3.6$ & 0.406 \\
\hline Struma & $2(1.9)$ & 0 & & & \\
\hline Strumectomy & $2(1.9)$ & I (I2.5) & & & \\
\hline Nervous system disorders & $\mathrm{n}=\mathbf{2 2}$ & $n=4$ & 0.5 & $0.2-1.6$ & 0.246 \\
\hline Chronic lumbago & 0 & I (I2.5) & & & \\
\hline Disc herniation & $2(1.9)$ & 0 & & & \\
\hline Polyneuropathy & $3(2.8)$ & I (I2.5) & & & \\
\hline Parkinson disease & $5(4.7)$ & 0 & & & \\
\hline Spinal canal stenosis & I (0.9) & I (I2.5) & & & \\
\hline State after stroke & II (10.4) & I (I2.5) & & & \\
\hline Orthopedic disorders & $n=13$ & $n=3$ & 0.4 & $0.1-1.5$ & 0.177 \\
\hline Osteoarthritis & $7(6.6)$ & $2(25)$ & & & \\
\hline Osteoporosis & $4(3.8)$ & I (I2.5) & & & \\
\hline Rheumatism & $2(1.9)$ & 0 & & & \\
\hline
\end{tabular}


Table 2 (Continued)

\begin{tabular}{|c|c|c|c|c|c|}
\hline & CAD $(n=106)(\%)$ & Without CAD $(n=8)(\%)$ & Odds ratio & $95 \% \mathrm{Cl}$ & $P$-value \\
\hline Psychiatric disorders & $n=4$ & $\mathbf{n}=\mathbf{0}$ & 0.9 & $0.05-17.7$ & 0.960 \\
\hline Dementia & $2(1.9)$ & 0 & & & \\
\hline Depression & $2(1.9)$ & 0 & & & \\
\hline Ear, nose, and throat disease & $\mathbf{n}=\mathbf{2}$ & $\mathbf{n}=\mathbf{0}$ & 0.5 & $0.02-10.9$ & 0.668 \\
\hline Nasal polypectomy & I (0.9) & 0 & & & \\
\hline Tonsillectomy & I (0.9) & 0 & & & \\
\hline Skin disorders & $\mathbf{n}=\mathbf{2}$ & $\mathbf{n}=\mathbf{0}$ & 0.5 & $0.02-10.9$ & 0.668 \\
\hline Allergy & I (0.9) & 0 & & & \\
\hline State post-herpes zoster & I (0.9) & 0 & & & \\
\hline Ophthalmologic diseases & $n=8$ & $\mathbf{n}=\mathbf{I}$ & 0.8 & $0.1-6.6$ & 0.828 \\
\hline Gynecological disorders & $\mathbf{n}=3$ & $\mathbf{n}=\mathbf{0}$ & 0.7 & $0.04-14.3$ & 0.828 \\
\hline State after breast cancer & $3(2.8)$ & 0 & & & \\
\hline Total number of diseases & 251 & 25 & & & \\
\hline
\end{tabular}

Notes: Significant $P$-values are shown in bold. The percentages refer to the total of number of patients in each group.

Abbreviations: $\mathrm{CAD}$, coronary artery disease; $\mathrm{Cl}$, confidence interval.

no NSTEMI or STEMI. The author also found no statistical difference between risk factors and acute comorbidities in the two groups (Table 5). Patients with acute comorbidities such as falls, attacks of gout, and delirium were less likely to have CAD (Table 5). These acute comorbidities showed no increased risk for CAD. In addition, chronic comorbidities also exhibited no increased risk for CAD (Table 2).

The duration of hospital stays was $6.3 \pm 9$ days in the study group and $7.5 \pm 7.8$ days in the control group, exhibiting no statistical significance $(P=0.756)$. There were three $(2.8 \%$, three $[100 \%$ ] female, $95 \% \mathrm{CI}:-0.3$ to 6$)$ deaths in the study group and no deaths in the control group $(P=0.630)$. Thus, the survival rate was $97.2 \%$ (95\% CI: $94-100.4)$ in the study group and $100 \%$ in the control group.

\section{Discussion}

After completing this study, the author found that for patients aged $>90$ years, only those with hypertension had a high risk for CAD. Traditional cardiovascular risk factors such as progressing age, diabetes mellitus, hypertension, dyslipidemia, smoking, and obesity are well-accepted for their relationship with CAD. ${ }^{47,48}$ Diabetes provided no increased risk for the development of CAD without statistical significance, and smoking presented absolutely no increased risk for CAD in the analysis of this study. Surprisingly, there was a low number of patients with hypercholesterolemia, which cannot be explained by prescription of statins for patients with acute myocardial infarction. The reason for the low number of patients with hypercholesterolemia was not studied in detail by this study. While the number of male patients with CAD was found to be slightly increased in this study, the author could not find a statistical difference in sex, with no increased risk for CAD. The severity of CAD in the elderly seemed to correlate poorly with the prevalence of established traditional cardiovascular risk factors.

Moreover, the predictive power of cardiovascular risk factors for CAD was also found to be weak in previous studies. According to the results of previous studies, the traditional cardiovascular risk factors did not correlate well with cardiac morbidity and mortality. ${ }^{49,50}$

$\mathrm{CAD}$ is often responsible for a deterioration of quality of life or mortality in the elderly. In addition, CAD prevention is often

Table 3 Comparison of cardiovascular risk factors in different forms of CAD

\begin{tabular}{lllll}
\hline Risk factors & CAD & & & P-value \\
\cline { 2 - 4 } & I-vessel (n=13) (\%) & 2-vessel (n=4 I) (\%) & 3-vessel (n=52) (\%) \\
\hline Hypertension & II (84.6) & $34(82.9)$ & $44(84.6)$ & 0.999 \\
Diabetes & $3(23.1)$ & $9(22)$ & $20(38.5)$ & 0.216 \\
Hypercholesterolemia & 0 & 0 & $2(3.9)$ & 0.617 \\
Hyperlipidemia & $3(23.1)$ & II (26.8) & $12(23.1)$ & 0.949 \\
Obesity & I (7.7) & I (2.4) & $2(3.9)$ & 0.599 \\
Smoker & 0 & 0 & $4(7.7)$ & 0.175 \\
Former smoker & 0 & $3(7.3)$ & $8(15.4)$ & $0.29 \mid$ \\
\hline
\end{tabular}

Abbreviation: CAD, coronary artery disease. 
Table 4 Comparison of cardiovascular risk factors in different forms of myocardial infarction

\begin{tabular}{|c|c|c|c|c|c|}
\hline \multirow[t]{2}{*}{ Risk factors } & \multicolumn{2}{|l|}{ CAD } & \multirow[t]{2}{*}{ NSTEMI $(n=36)(\%)$} & \multirow[t]{2}{*}{ STEMI $(n=27)(\%)$} & \multirow[t]{2}{*}{$P$-value } \\
\hline & $\begin{array}{l}\text { Stable angina } \\
(n=21)(\%)\end{array}$ & $\begin{array}{l}\text { Unstable angina } \\
(n=79)(\%)\end{array}$ & & & \\
\hline Hypertension & $21(100)$ & $63(79.8)$ & $28(77.8)$ & $19(70.4)$ & 0.072 \\
\hline Diabetes & $6(28.6)$ & $23(29.1)$ & $13(36.1)$ & $4(14.8)$ & 0.317 \\
\hline Hypercholesterolemia & 0 & $2(2.5)$ & 0 & I (3.7) & 0.615 \\
\hline Hyperlipidemia & $6(28.6)$ & $19(24.1)$ & $9(25)$ & $5(18.5)$ & 0.871 \\
\hline Obesity & 0 & $4(5.1)$ & $3(8.3)$ & 0 & 0.296 \\
\hline Smoker & $2(9.5)$ & $2(2.5)$ & $2(5.6)$ & 0 & 0.295 \\
\hline Former smoker & $2(9.5)$ & $9(11.4)$ & $6(16.7)$ & I (3.7) & 0.440 \\
\hline
\end{tabular}

Abbreviations: CAD, coronary artery disease; NSTEMI, non-ST-segment elevation myocardial infarction; STEMI, ST-segment elevation myocardial infarction.

underused in this population. CAD can be prevented through antihypertensive drugs in elderly patients with hypertension. Not only treatment for hyperlipidemia, but also treatment of high-risk elderly persons by statins and antiplatelet agents, might minimize the risk of CAD. Heart failure can also be prevented in the elderly. Lifestyle changes should be encouraged in older persons, particularly smoking cessation, increased physical activity, and a Mediterranean-type diet; these factors appear to have greater positive effects on cardiovascular health in the elderly than in younger adults. ${ }^{51}$ While hypertension was treated by medication in the very elderly, the present study showed that the risk for CAD was high. Hyperlipidemia exhibited no increased risk for CAD in the very elderly in our study population. The prevention of heart failure via the

Table 5 Comparison of acute illnesses in patients with and without CAD

\begin{tabular}{|c|c|c|c|c|c|}
\hline & CAD $(n=106)(\%)$ & Without CAD $(n=8)(\%)$ & Odds ratio & $95 \% \mathrm{Cl}$ & $P$-value \\
\hline Cardiovascular diseases & $n=123$ & $n=14$ & 1.7 & $0.6-4.8$ & 0.314 \\
\hline Acute heart failure & $95(89.6)$ & $8(100)$ & & & \\
\hline Anemia & $4(3.8)$ & 0 & & & \\
\hline Cardiac decompensation & $14(13.2)$ & $2(25)$ & & & \\
\hline Circulatory collapse & $\mathrm{I}(0.9)$ & 0 & & & \\
\hline Derailed blood pressure & $7(6.6)$ & 0 & & & \\
\hline Shock & I (0.9) & 0 & & & \\
\hline Syncope & I (0.9) & $4(50)$ & & & \\
\hline Pulmonary disease & $\mathrm{n}=\mathbf{8}$ & $n=2$ & 0.5 & $0.1-2.5$ & 0.394 \\
\hline Acute respiratory failure & $2(1.9)$ & $\mathrm{I}(12.5)$ & & & \\
\hline Aspiration pneumonia & I (0.9) & 0 & & & \\
\hline Bronchopulmonary infection & $3(2.8)$ & $\mathrm{I}(12.5)$ & & & \\
\hline Pneumonia & I (0.9) & 0 & & & \\
\hline Pulmonary edema & I (0.9) & 0 & & & \\
\hline Gastrointestinal diseases & $n=4$ & $\mathbf{n}=\mathbf{0}$ & 1.2 & $0.1-23.6$ & 0.893 \\
\hline Duodenal ulcer & I (0.9) & 0 & & & \\
\hline Gastrointestinal bleeding & $2(1.8)$ & 0 & & & \\
\hline Reflux esophagitis & I (0.9) & 0 & & & \\
\hline Kidney disease & $n=13$ & $\mathbf{n}=\mathbf{I}$ & 1.8 & $0.2-14.2$ & 0.599 \\
\hline Acute kidney injury & $3(2.8)$ & 0 & & & \\
\hline Acute urinary tract infection & $7(6.6)$ & $\mathrm{I}(\mathrm{I} 2.5)$ & & & \\
\hline Macrohematuria & $3(2.8)$ & 0 & & & \\
\hline Thyroid disease & $\mathbf{n}=\mathbf{5}$ & $\mathbf{n}=\mathbf{0}$ & 1.5 & $0.1-28.3$ & 0.784 \\
\hline Hyperthyroidism & I (0.9) & 0 & & & \\
\hline Hypothyroidism & $4(3.8)$ & 0 & & & \\
\hline Other conditions & $\mathbf{n}=\mathbf{I}$ & $n=3$ & 0.03 & $0.004-0.4$ & 0.005 \\
\hline Fall & 0 & I (12.5) & & & \\
\hline Attack of gout & 0 & I (12.5) & & & \\
\hline Delirium & I (0.9) & I (I2.5) & & & \\
\hline Total number of diseases & 154 & 20 & & & \\
\hline
\end{tabular}

Notes: Significant $P$-values are shown in bold. The percentages refer to the total of number of patients in each group.

Abbreviations: $\mathrm{CAD}$, coronary artery disease; $\mathrm{Cl}$, confidence interval. 
administration of appropriate drugs is also very difficult in the aging hearts of the very elderly. Compliance may deteriorate as a result of various circumstances, such as in elderly patients with dementia, although very elderly people with dementia were found in this study to have no increased risk of CAD.

Smokers were underrepresented in this study. According to the results, smoking plays no role at an advanced age. Former smoking in earlier years also presented no increased risk of CAD for the elderly in the current study. However, the damaging effects of tobacco smoking on health are certainly not in question among the very elderly, as in other populations. The effects of smoking on mortality in the elderly population has been studied previously. ${ }^{52}$ When comparing the mortality rates for older smokers, ex-smokers, and nonsmokers, lower mortality was observed for nonsmokers and former smokers compared to older smokers. ${ }^{52}$ Although no direct evidence was available, it is desirable for older smokers to stop smoking. Smoking cessation is certainly a health benefit for older smokers, not to mention the high costs incurred by smoking.

Obesity was not an increased risk factor for CAD in very elderly patients in this study. The same result was reported by Kim et al in relation to the elderly. ${ }^{53}$ These results raise questions about the value of weight loss and diet for the prevention of CAD in the elderly.

Acute and chronic comorbidities were not predictors of CAD in the very elderly in the present study. Female sex, hypertension, and comorbidity were greater predictors of $\mathrm{CAD}$ in the elderly than in younger patients in the study by Mogensen et al. ${ }^{54}$ Mogensen et al found that the prevalence of cardiovascular comorbidities increased with advancing age only until the seventh decade and then declined, resulting in the lowest prevalence of diabetes, hypertension, ischemic heart disease, and peripheral artery disease among the very elderly aged $>85$ years compared with patients aged $<85$ years. Noncardiovascular comorbidities generally increased linearly with age. ${ }^{54}$

Veeranna et al reported that age and male sex, but not hypertension or dyslipidemia, represented an increased risk for CAD. Only diabetes was an independent predictor of CAD, and smoking was associated with the occlusion of the left main trunk artery of the heart in their study. ${ }^{55}$ However, it should be noted that the difference in mean age was more than 20 years between Veeranna et al's population and that of this current study. It could be that the risk profile of CAD is different in people in their 70s. This was very different from the outcome of this study, as the author of the present study found a high risk of CAD related to hypertension in very elderly people.
The associations of some risk factors for $\mathrm{CAD}$ are reduced in older age, while other risk factors in old age remain constantly detectable. One study examined all elderly patients according to age groups regarding cardiovascular risk factors. The associations of most traditional risk factors with CAD were insignificant in the very elderly in the previous study reported by Odden et al. ${ }^{56}$ The link between hypertension and diabetes with age was strongest in the study by Odden et al. ${ }^{56}$

However, it continues to be difficult to correlate CAD and atherosclerosis. Even though this has been evaluated angiographically, the connection has not been well-established, and previous studies have reported different and varying outcomes concerning the link between CAD and atherosclerosis. ${ }^{57-59}$

Although the Framingham Risk Score assessment tool can be used to estimate a patient's 10-year risk of developing CAD, this score was not considered in the present study, as this score underrates the CAD risk in the elderly, and particularly women; in contrast, traditional risk factors represent the best predictors of CAD. ${ }^{60}$

\section{Study limitations}

This study examined the traditional risk factors for CAD in very elderly people in a single-center department of internal medicine but did not investigate the very elderly with CAD in other medical departments. A generalization should therefore not be concluded from the results of a study in only one department of a hospital. Another limitation was that the author was unable to identify very elderly patients with ACS who had not undergone cardiac catheterization for any reason. Moreover, aging itself was considered to be a risk factor for CAD in previous studies. It is also possible that the risk profiles change over time among age groups. The influence of lifestyle and diet on the traditional risk factors were not considered in the very elderly in this study. Therefore, it is difficult to identify the risk profile for CAD in very elderly people. Various causes of the development for CAD have been discussed in the current scientific/medical literature. The number of the very elderly aged $>90$ years was relatively small for drawing any generalized conclusions. Cardiac catheterization may not be the best and most appropriate investigation through which to diagnose CAD, particularly in this age group.

\section{Conclusion}

The author was able to demonstrate an increased risk in the prevalence of hypertension in patients aged $>90$ years with CAD. However, more attention needs to be paid particularly to the therapy of hypertension as established risk factors in 
addition to diabetes, hyperlipidemia, obesity, and smoking in the therapeutic management and prevention of CAD in very elderly people, in addition to treatment for acute and chronic comorbidities.

\section{Disclosure}

The author reports no conflicts of interest in this work.

\section{References}

1. Exarchos KP, Exarchos TP, Bourantas CV, et al. Prediction of coronary atherosclerosis progression using dynamic Bayesian networks. Conf Proc IEEE Eng Med Biol Soc. 2013;2013:3889-3892.

2. Schoenhagen P, Tuzcu EM, Apperson-Hansen C, et al. Determinants of arterial wall remodeling during lipid-lowering therapy: serial intravascular ultrasound observations from the Reversal of Atherosclerosis with Aggressive Lipid Lowering Therapy (REVERSAL) trial. Circulation. 2006;113(24):2826-2834.

3. de Graaf MA, Broersen A, Kitslaar PH, et al. Automatic quantification and characterization of coronary atherosclerosis with computed tomography coronary angiography: cross-correlation with intravascular ultrasound virtual histology. Int J Cardiovasc Imaging. 2013;29(5):1177-1190.

4. Priester TC, Litwin SE. Measuring progression of coronary atherosclerosis with computed tomography: searching for clarity among shades of gray. J Cardiovasc Comput Tomogr. 2009;3 Suppl 2:S81-S90.

5. Martin SS, Abd TT, Jones SR, Michos ED, Blumenthal RS, Blaha MJ. 2013 ACC/AHA cholesterol treatment guideline: what was done well and what could be done better. J Am Coll Cardiol. 2014;63(24): 2674-2678.

6. Kavousi M, Leening MJ, Nanchen D, et al. Comparison of application of the ACC/AHA guidelines, Adult Treatment Panel III guidelines, and European Society of Cardiology guidelines for cardiovascular disease prevention in a European cohort. JAMA. 2014;311(14):1416-1423.

7. Fihn SD, Gardin JM, Abrams J, et al; American College of Cardiology Foundation; American Heart Association Task Force on Practice Guidelines; American College of Physicians; American Association for Thoracic Surgery; Preventive Cardiovascular Nurses Association; Society for Cardiovascular Angiography and Interventions; Society of Thoracic Surgeons. 2012 ACCF/AHA/ACP/AATS/PCNA/SCAI/STS Guideline for the diagnosis and management of patients with stable ischemic heart disease: a report of the American College of Cardiology Foundation/American Heart Association Task Force on Practice Guidelines, and the American College of Physicians, American Association for Thoracic Surgery, Preventive Cardiovascular Nurses Association, Society for Cardiovascular Angiography and Interventions, and Society of Thoracic Surgeons. J Am Coll Cardiol. 2012; 60(24):e44-e164.

8. Perk J, De Backer G, Gohlke H, et al; European Association for Cardiovascular Prevention \& Rehabilitation (EACPR); ESC Committee for Practice Guidelines (CPG). European Guidelines on cardiovascular disease prevention in clinical practice (version 2012). The Fifth Joint Task Force of the European Society of Cardiology and Other Societies on Cardiovascular Disease Prevention in Clinical Practice (constituted by representatives of nine societies and by invited experts). Eur Heart $J$. 2012;33(13):1635-1701.

9. Alexander KP, Newby LK, Cannon CP, et al; American Heart Association Council on Clinical Cardiology; Society of Geriatric Cardiology. Acute coronary care in the elderly, part I: non-ST-segment-elevation acute coronary syndromes: a scientific statement for healthcare professionals from the American Heart Association Council on Clinical Cardiology: in collaboration with the Society of Geriatric Cardiology. Circulation. 2007;115(19):2549-2569.
10. Preik M, Kelm M, Strauer BE. Management of the hypertensive patient with coronary insufficiency but without atherosclerosis. Curr Opin Cardiol. 2003;18(4):255-259.

11. Cai Q, Mukku VK, Ahmad M. Coronary artery disease in patients with chronic kidney disease: a clinical update. Curr Cardiol Rev. 2013;9(4):331-339.

12. Curran SA, Hollan I, Erridge C, et al. Bacteria in the adventitia of cardiovascular disease patients with and without rheumatoid arthritis. PLoS One. 2014;9(5):e98627.

13. Liuzzo G. Atherosclerosis: an inflammatory disease. Rays. 2001; 26(4):221-230.

14. Lind L. Circulating markers of inflammation and atherosclerosis. Atherosclerosis. 2003;169(2):203-214.

15. Libby P. Inflammation in atherosclerosis. Nature. 2002;420(6917): 868-874.

16. Williams KJ, Tabas I. The response-to-retention hypothesis of atherogenesis reinforced. Curr Opin Lipidol. 1998;9(5):471-474.

17. Ostadal B, Ostadalova I, Kolar F, Sedmera D. Developmental determinants of cardiac sensitivity to hypoxia. Can J Physiol Pharmacol. 2014;92(7):566-574.

18. Valgimigli M, Biscaglia S. Stable angina pectoris. Curr Atheroscler Resp. 2014;16(7):422.

19. Gorenek B, Kudaiberdieva G. Arrhythmic emergencies in ICCU. Minerva Med. 2013;104(4):383-390.

20. Böhm M, Pogue J, Kindermann I, Pöss J, Koon T, Yusuf S. Effect of comorbidities on outcomes and angiotensin converting enzyme inhibitor effects in patients with predominantly left ventricular dysfunction and heart failure. Eur J Heart Fail. 2014;16(3):325-333.

21. Schlett CL, Nance JW Jr, Schoepf UJ, et al. Differences in coronary artery disease by $\mathrm{CT}$ angiography between patients developing unstable angina pectoris vs major adverse cardiac events. Eur J Radiol. 2014; 83(7):1113-1119.

22. Meier P, Lansky AJ, Baumbach A. Almanac 2013: acute coronary syndromes. Acta Cardiol. 2014;69(1):100-108.

23. Israel CW. Mechanisms of sudden cardiac death. Indian Heart $J$. 2014;66 Suppl 1:S10-S17.

24. Fuster V, Kovacic JC. Acute coronary syndromes: pathology, diagnosis, genetics, prevention and treatment. Circ Res. 2014;114(12): $1847-1851$.

25. Prapas SN, Tsakiridis K, Zarogoulidis P, et al. Current options for treatment of chronic coronary artery disease. J Thorax Dis. 2014; 6 Suppl 1:S2-S6.

26. Akhabue E, Thiboutot J, Cheng JW, et al. New and emerging risk factors for coronary heart disease. Am J Med Sci. 2014;347(2):151-158.

27. Wilson PW. Assessing coronary heart disease risk with traditional and novel risk factors. Clin Cardiol. 2004;27(6 Suppl 3):III7-III11.

28. Eaton CB. Traditional and emerging risk factors for cardiovascular disease. Prim Care. 2005;32(4):963-976, vii.

29. Lee MS, Fammer AJ, Li J, et al. Time-trend analysis on the Framingham risk score and prevalence of cardiovascular risk factors in patients undergoing percutaneous coronary intervention without prior history of coronary vascular disease over the last 17 years: a study from the Mayo Clinic PCI Registry. Clin Cardiol. 2014;37(7):408-416.

30. Ford ES. Trends in predicted 10 -year risk of coronary heart disease and cardiovascular disease among U.S. adults from 1999 to 2010. J Am Coll Cardiol. 2013;61(22):2249-2252.

31. Onat A, Hergenç G, Can G, Uğur M, Nartop F. Dual activity of serum lipoprotein-associated phospholipase $\mathrm{A}(2)$ yielding positive and inverse associations with cardiometabolic risk. Clin Chem Lab Med. 2011;49(8):1349-1357.

32. Rosen RS, Elliott M, Stasiv Y, Hisop C; PLASMA II Investigators. Randomized trial of an inhibitor of secretory phospholipase A2 on atherogenic lipoprotein subclasses in statin-treated patients with coronary heart disease. Eur Heart J. 2011;32(8):999-1005.

33. Pirillo A, Norata GD, Catapano AL. Treating high density lipoprotein cholesterol (HDL-C): quantity versus quality. Curr Pharm Des. 2013; 19(21):3841-3857. 
34. Mallaina P, Lionis C, Rol H, et al. Smoking cessation and the risk of cardiovascular disease outcomes predicted from established risk scores: results of the Cardiovascular Risk Assessment among Smokers in Primary Care in Europe (CV-ASPIRE) study. BMC Public Health. 2013;13:362.

35. Escobar E. Hypertension and coronary heart disease. J Hum Hypertens. 2002;16 Supp1 1:S61-S63.

36. Shah BS, Deshpande SS. Assessment of demographics, treatment strategies, and evidence-based medicine use among diabetic and non-diabetic patients with acute coronary syndrome: a cohort study. J Pharmacol Pharmacother. 2014;5(2):139-144.

37. Franklin BA, Durstine JL, Roberts CK, Barnard RJ. Impact of diet and exercise on lipid management in the modern era. Best Pract Res Clin Endocrinol Metba. 2014;28(3):405-421.

38. Breeman A, Hordijk-Trion M, Lenzen M, et al; Euro Heart Survey on Coronary Revascularization. Treatment decisions in stable coronary artery disease: insights from the Euro Heart Survey on Coronary Revascularization. J Thorac Cardiovasc Surg. 2006;132(5):1001-1009.

39. Ferreira-González I. The epidemiology of coronary heart disease. Rev Esp Cardiol (Engl Ed). 2014;67(2):139-144.

40. Howard G, Manolio TA, Burke GL, Wolfson SK, O’Leary DH. Does the association of risk factors and atherosclerosis change with age? An analysis of the combined ARIC and CHS cohorts. The Atherosclerosis Risk in Communities (ARIC) and Cardiovascular Health Study (CHS) investigators. Stroke. 1997;28(9):1693-1701.

41. Kim MJ, Rolland Y, Cepeda O, Gammack JK, Morley JE. Diabetes mellitus in older men. Aging Male. 2006;9(3):139-147.

42. Pearte CA, Furberg CD, O'Meara ES, et al. Characteristics and baseline clinical predictors of future fatal versus nonfatal coronary heart disease events in older adults: the Cardiovascular Health Study. Circulation. 2006;113(18):2177-2185.

43. Lee PY, Alexander KP, Hammill BG, Pasquali SK, Peterson ED. Representation of elderly persons and women in published randomized trials of acute coronary syndromes. JAMA. 2001;286(6):708-713.

44. Levine GN, Bates ER, Blankenship JC, et al. 2011 ACCF/AHA/SCAI Guideline for Percutaneous Coronary Intervention: executive summary: a report of the American College of Cardiology Foundation/American Heart Association Task Force on Practice Guidelines and the Society for Cardiovascular Angiography and Interventions. Circulation. 2011;124(23):2574-2609.

45. Expert Dyslipidemia Panel of the International Atherosclerosis Society Panel members. An International Atherosclerosis Society Position Paper: global recommendations for the management of dyslipidemia - full report. J Clin Lipidol. 2014;8(1):29-60.

46. Whitworth JA; World Health Organization, International Society of Hypertension Writing Group. 2003 World Health Organization (WHO)/ International Society of Hypertension (ISH) statement on management of hypertension. J Hypertens. 2003;21(11):1983-1992.
47. Rosamond W, Flegal K, Furie K, et al; American Heart Association Statistics Committee and Stroke Statistics Subcommittee. Heart disease and stroke statistics - 2008 update: a report from the American Heart Association Statistics Committee and Stroke Statistics Subcommittee. Circulation. 2008;117(4):e25-e146.

48. Greenland P, Knoll MD, Stamler J, et al. Major risk factors as antecedents of fatal and nonfatal coronary heart disease events. JAMA. 2003;290(7):891-897.

49. Mukamal KJ, Kronmal RA, Tracy RP, Cushman M, Siscovick DS. Traditional and novel risk factors in older adults: cardiovascular risk assessment late in life. Am J Geriatr Cardiol. 2004;13(2):69-80.

50. Ness J, Aronow WS, Ahn C. Risk factors for coronary artery disease in old persons in an academic hospital-based geriatrics practice. Coron Artery Dis. 2000;11(5):437-439.

51. Belmin J, Chauvelier S, Friocourt P. [Prevention of coronary heart disease and heart failure in the elderly]. Rev Prat. 2009;59(10):1389-1395. French.

52. Gentleman JF, Brown KS, Forbes WF. Smoking and its effect on mortality of the elderly. Am J Med Sci. 1978;276(2):173-183.

53. Kim DJ, Bergstrom J, Barrett-Connor E, Laughlin GA. Visceral adiposity and subclinical coronary artery disease in elderly adults: Rancho Bernardo Study. Obesity (Silver Spring). 2008;16(4):853-858.

54. Mogensen UM, Erbøll M, Andersen M, et al. Clinical characteristics and major comorbidities in heart failure patients more than 85 years of age compared with younger age groups. Eur J Heart Fail. 2011;13(11):1216-1223.

55. Veeranna V, Pradhan J, Niraj A, Fakhry H, Afonso L. Traditional cardiovascular risk factors and severity of angiographic coronary artery disease in the elderly. Prec Cardiol. 2010;13(3):135-140.

56. Odden MC, Shlipak MG, Whitson HE, et al. Risk factors for cardiovascular disease across the spectrum of older age: The Cardiovascular Health Study. Atherosclerosis. 2014;237(1):336-342.

57. Gehnai AA, al-Mulla AW, Chaikhouni A, et al. Myocardial infarction with normal coronary angiography compared with severe coronary artery disease without myocardial infarction: the crucial role of smoking. J Cardiovasc Risk. 2001;8(1):1-8.

58. Da Costa A, Isaaz K, Faure E, Mourot S, Cerisier A, Lamaud M. Clinical characteristics, aetiological factors and long-term prognosis of myocardial infarction with an absolutely normal coronary angiogram; a 3-year follow-up study of 91 patients. Eur Heart J. 2001; 22(16):1459-1465.

59. Sun YH, Yang YJ, Pei WD, Wu YJ, Gao RL. Patients with low highdensity lipoprotein-cholesterol or smoking are more likely to develop myocardial infarction among subjects with a visible lesion or stenosis in coronary artery. Circ J. 2006;70(12):1602-1605.

60. Rodondi N, Locatelli I, Aujesky D, et al; Health ABC Study. Framingham risk score and alternatives for prediction of coronary heart disease in older adults. PLoS One. 2012;7(3):e34287.
Clinical Interventions in Aging

\section{Publish your work in this journal}

Clinical Interventions in Aging is an international, peer-reviewed journal focusing on evidence-based reports on the value or lack thereof of treatments intended to prevent or delay the onset of maladaptive correlates of aging in human beings. This journal is indexed on PubMed Central, MedLine,

\section{Dovepress}

CAS, Scopus and the Elsevier Bibliographic databases. The manuscript management system is completely online and includes a very quick and fair peer-review system, which is all easy to use. Visit http://www.dovepress. com/testimonials.php to read real quotes from published authors. 